\title{
O DISCURSO DO FRACASSO ESCOLAR NA PEDAGOGIA CRÍTICA
}

\author{
Maria do Socorro Nóbrega Queiroga \\ Universidade Federal da Paraíba \\ socorroqueiroga@gmail.com
}

\section{RESUMO:}

Este ensaio é parte de uma discussão desenvolvida em Tese de Doutorado, tratando dos discursos sobre fracasso escolar, no contexto mais amplo dos discursos sobre as crianças com trajetórias minoritárias na escola, atrelados às relações de poder. No trato com a análise dos discursos utilizei como ferramenta teórica central a analítica de Michel Foucault -, sobretudo sua importante contribuição sobre as relações de poder e a produção de saber, e a perspectiva histórico-sociológica de Norbert Elias e Philippe Arriès. Compreendendo os discursos sobre o fracasso escolar como maquinarias de governo da infância, analiso-os como formas de disciplinamento fabricadas para regular as trajetórias individuais e como forma de controle da população, em diferentes tempos históricos, e, que buscam capturar os sujeitos através dos saberes produzidos, sobretudo no campo "psi" e pedagógico. $\mathrm{Na}$ Tese elegi três séries históricas nas quais as trajetórias escolares das crianças são significadas de diferentes formas: a série da "eugenia", desde finais do século XIX até as quatro primeiras décadas do século XX; a série do "planejamento" - entre os anos de 1960/1980, objeto deste artigo, e a série da "eficácia", entre os anos 1980 até a contemporaneidade.

Palavras-chave: Educação. Infância. Fracasso escolar. Discurso crítico.

\section{THE DISCOURSE OF FAILURE SCHOOL IN CRITICAL PEDAGOGY}

\begin{abstract}
:
This article is a part of a discussion developed on Doctoral Dissertation treating a discuss about failure school in the broader discourse about children with minor trajectory in school, tied to power relations. In dealing with the analysis of discourses I used as the analytical tool of central theoretical Michel Foucault - especially his important contribution on the relations of power and knowledge production and historical-sociological approach of Norbert Elias and Philippe Arries. Understanding the discourses on failure school of government machinery as childhood, I analyze them as forms of discipline made to regulate the individual trajectories and as a way of population control in different historical times and seeking to capture the subjects knowledge through produced especially in the psychological and pedagogical areas. In the thesis I have chosen three series in which the school trajectories of children are meant in different ways: a series of "eugenics" from the late nineteenth century until the first four decades of the twentieth century, a series of "planning" - between the years for 1960/1980, subject of this article, and the series of "efficiency" between the years 1980 until the present.
\end{abstract}

Keywords: education, childhood, failure school, critical discussion. 


\title{
INTRODUÇÃO
}

\author{
O tempo é de cuidados, companheiro. \\ É tempo sobretudo de vigília. \\ O inimigo está solto e se disfarça, \\ mas como usa botinas, fica fácil \\ distinguir-lhe o tacão grosso e lustroso, \\ que pisa as forças claras da verdade \\ e esmaga os verdes que dão vida ao chão. \\ O tempo é de mentira. (MELLO, 1978, p. 24).
}

O prólogo acima trata das décadas de setenta do Século XX como "um tempo de mentira"; e também um tempo de "cuidados", pois um "inimigo está solto e se disfarça", impossibilitando a todos o conhecimento da "verdade". A "fala" do poeta Thiago de Melo é símbolo da descontinuidade dos discursos até então produzidos no Brasil, no campo da educação e da política educacional. As produções, de modo geral, partiam de uma visão liberal de educação, constituída por metanarrativas que serviam de lastro para a constituição dos saberes, dos discursos e das práticas não discursivas sobre a educação, de modo geral, e do fracasso escolar, em particular, temática a ser problematizada neste ensaio.

Especificamente em relação ao discurso liberal, seus enunciados compunham um quadro cujo desenho liga os saberes das filosofias essencialistas, da psicologia humanista e da pedagogia tradicional e tecnicista, articulados por outros enunciados relacionados aos alunos, no sentido de uma suposta luta por "autonomia", entre outros. Todos esses referentes tecem as tramas e os movimentos que definem as expectativas e operacionalizam funções e práticas educativas no interior da escola, enredados por uma ideia central e mobilizadora: a de "mudança" da sociedade e/ou da escola e/ou do aluno etc. (BUJES, 2002; 2003).

O presente texto é parte de um estudo realizado em Tese de Doutorado ${ }^{\mathrm{i}}$, que trata dos discursos sobre as crianças com trajetórias minoritárias na escola e os conceitos que os articulam; sobre a ordem e o regime de verdade que possibilitaram a emergência dos discursos sobre a infância, suas condições de produção, suas continuidades e rupturas. Essas trajetórias foram traduzidas na realidade escolar brasileira e na literatura acadêmica de diferentes modos e com diferentes matizes ideológicas. ${ }^{\text {ii }}$

$\mathrm{Na}$ Tese mencionada (2005), utilizo, como referencial para a análise dos documentos, o método arqueológico de Foucault. (MACHADO, 2000) Assim, estabeleci eixos (infância e educação) que me possibilitaram fazer uma leitura dos discursos produzidos sobre as crianças com trajetórias minoritárias na escola, nos quais se insere a formação discursiva do fracasso escolar.

Esses discursos foram categorizados em três séries históricas: a série do eugenismo, predominante desde meados do Século XIX até a década de trinta do Século XX; a série do discurso do planejamento - que compreende o período entre a década de 1960 e 1980 do Século XX - e a série do discurso da eficácia - de meados dos anos de 1980 até a contemporaneidade.

O recorte deste artigo será articular a discussão sobre as crianças com trajetórias minoritárias na escola com uma série histórica específica - a série do planejamento. Contrapondo-se a esse viés, que naturaliza a educação, destituindo-a de seu caráter social e 
histórico, um novo território delineia-se no cenário brasileiro, o discurso crítico. Representado por publicações diversas de livros, artigos de revistas, teses e dissertações, toma como eixo de articulação para seus enunciados a relação entre sociedade e educação, predominantemente numa perspectiva marxista. Articulando alguns conceitos centrais do Materialismo Histórico, as vertentes pedagógicas críticas interrogam a sociedade e a escola no que tange à exclusão das camadas populares nas sociedades capitalistas, os modos como se dão as relações de produção, uma narrativa que vai "ao" encontro de duas frentes e "de" encontro a elas.

A primeira frente refere-se às produções que tematizam e problematizam o Estado e o capitalismo, as práticas pedagógicas, os conteúdos ideológicos dos livros didáticos, a teoria do capital humano e seus defensores, a universidade e o pensamento educacional brasileiro, entre outras. São produções de uma época em que predominam fortemente os discursos jurídicos - encetados pela governamentalidade estatal militar - sobre a "distensão" política, com o governo de Ernesto Geisel (1974-1979), a "abertura" política, com João Figueiredo (1979-1985) e o apelo ao "Brasil-potência", o fim do AI-5 e a anistia.

A segunda frente estava constituída e repercutiu através dos discursos jurídicos, no campo educacional, caracterizados pela exacerbação de dados estatísticos que legitimavam uma (suposta) preocupação dos poderes públicos com a ampliação das oportunidades de acesso à educação escolar. ${ }^{\text {iii }}$

Parcelas da população em luta, junto com parte significativa de educadores/as, voltavam-se a se preocupar com a permanência das crianças das camadas populares no processo escolar, já que os índices de repetência e de evasão destoavam dos discursos do "Brasil-potência" e da teoria do capital humano, com um acento especial sobre as "crianças pobres", a "participação" dos "carentes", a "educação no meio rural", a "educação nas periferias urbanas", as "insuficiências da educação formal" e o caráter "compensatório" da educação pré-escolar. ${ }^{\text {iv }}$ Nesse sentido, o próprio Ministro da Educação assim se expressou: "Isso era um dever de Estado, a democratização do ensino era um duplo imperativo, um imperativo ético e um imperativo político". (PASSARINHO, Jarbas, 1986 apud GERMANO, 2000, p.168)

Estudos da época são reveladores das condições das novas políticas desenvolvidas, como a ampliação das vagas na rede pública de ensino, cujo foco era o aspecto quantitativo do acesso. As possibilidades de entrar na escola e de nela permanecer, até o final dos estudos, tinha um alto preço, que era a sua baixa qualidade. ${ }^{v}$ Nessa época, foram enormemente subtraídas as despesas com educação - em dez pontos percentuais, entre 1981 e 1985, sem falar nas condições em que se encontrava a carreira para o Magistério, o nível de formação dos professores - com grande contingente de leigos e condições físicas precárias ou mesmo inexistentes do próprio espaço escolar.

Foi também nesse período em que as forças oposicionistas obtiveram maioria nas eleições em todo o país, e os movimentos sociais (sindicatos de trabalhadores, estudantes e professores, principalmente) e as instituições representativas da intelectualidade nacional como a Ordem dos Advogados do Brasil (OAB), a Sociedade Brasileira para o Progresso da Ciência (SBPC), a Associação Brasileira de Imprensa (ABI), a Universidade Estadual de Campinas (UNICAMP), entre outras - passaram a se manifestar mais incisiva e publicamente. (GERMANO, loc. cit.).

Os "territórios da revolta" que possibilitaram as críticas aos discursos hegemônicos, até então, no campo educacional, foram agenciados pelo paradigma marxista, ${ }^{\text {vi }}$ que "se arvora a ser o último dos discursos, a ser aquele que instauraria de vez o encontro entre as 
palavras e as coisas, entre a representação e o referente, entre o significante e o significado [...]”. (ALBUQUERQUE JÚNIOR, 2001, p. 185-186).

Mesmo inserido no campo educacional como o contraponto crítico dos discursos liberais predominantes nos anos de 1970, os discursos críticos são uma continuidade dos enunciados do discurso liberal, mas articulados a outros significados, compondo um novo quadro semântico e ideológico.

Sobre outro prisma semântico, a produção discursiva crítica repete a retórica do discurso protetor da infância escolar pobre, segundo uma concepção do poder significado como "soberania", ou seja, um poder que se submete à ordem do "príncipe" diretamente. E, assim, a busca pelas origens do poder, a partir da "classificação entre aqueles grupos que, estruturalmente, dominam e aqueles que são reprimidos. [...], deixa de reconhecer as qualidades disciplinares e produtivas do poder no processo de construção da pessoa autônoma e auto-reflexiva. [...] supõe estruturas e processos unificados e frequentemente evolutivos". (POPKEWITZ, 1998, p. 98).

As metanarrativas críticas apresentam-se atreladas ao campo das filosofias da consciência, cujos pressupostos humanistas da autonomia do sujeito e da sua consciência e os essencialismos correspondentes tomam como centralidade o mundo social e o sujeito. Supõem, então, que a qualidade e a quantidade da inserção dos indivíduos no mundo estão na dependência do nível de consciência por ele atingido: "a crença na construção de outro mundo ou de um novo mundo, purificado dos erros do presente" (ALBUQUERQUE JÚNIOR, 2001, p. 202), o que, de certo modo, nega a multiplicidade e a mundanidade que caracterizam a vida.

Trazendo a contribuição de Castoriadis (1992), importante para as reflexões nesse momento, a literatura da pedagogia crítica compreende a perspectiva marxiana em suas duas vertentes: o materialismo histórico e a luta de classes, elementos centrais na construção das narrativas e das obras.

Na primeira versão - a do materialismo histórico - a teoria se antecipa à prática, o que significa dizer que a missão histórica de transformação político-social cabe ao operariado urbano, mas só se realizará pela intervenção (externa) dos ideólogos socialistas, o que possibilita a formação de uma consciência revolucionária da classe operária. Segundo essa visão, no campo político, a posição exercida pelo partido é de grande relevância, e no campo educacional ou pedagógico mais estrito, a apropriação do saber sistematizado é produzido social e historicamente para as camadas populares.

Assim, é dada maior importância ao conteúdo a ser ensinado, pois a compreensão hegemônica era de que "as mudanças se fazem no plano dos conceitos, das ideias, e a ação concreta é colocada à margem. [...] É suficiente alterar o conteúdo a ser ensinado distribuir conteúdos mais críticos - para garantir uma consciência crítica e uma ação transformadora". (MARTINS, 1996, p. 87).

A segunda linha do pensamento teórico marxista - a luta de classes - parte do pressuposto de que cabem aos trabalhadores, através de suas lutas, as transformações político-sociais. Nesse sentido, a prática é valorizada em detrimento da teoria, a qual deveria ser expressão da ação - o que significa dizer, no campo político, uma valorização da ação prática consubstanciada na luta de classes.

No campo pedagógico escolar, corresponderiam mudanças na própria organização escolar, nas relações, no fazer pedagógico, de modo a privilegiar a prática dos alunos e os problemas postos por essa prática. Nessa perspectiva, "importa a sistematização coletiva de conhecimentos, em que o próprio processo de fazer passa a ser fundamental como 
elemento educativo. [...] As formas de ensinar, de transmitir, não são neutras [...] (mas) a expressão material de relações sociais no interior do capitalismo". (VEIGA, 1996, p. 88).

Segundo POPKEWITZ (1998, p. 98), mesmo as condições postas pelo capitalismo sendo elementos importantes para a organização do poder, não são suficientes como fundamento teórico adequado para se compreender como as capilaridades do poder funcionam na sociedade contemporânea. Diz ele: "Não existe um modelo único de capitalismo; tampouco existe uma história única de um desenvolvimento único, unificado". (ibidem).

A ideia da construção de um novo homem e de uma nova mulher, no ideário crítico, desloca-se ora de um sujeito coletivo, vivificado na "classe operária", ora nas lutas dos trabalhadores de modo geral, sob a contribuição fundamental dos intelectuais - entre eles/as, os/as professores/as -, mas de forma diferenciada, pois, segundo Silva (2000), os intelectuais se reconhecem na versão crítica, como "fora do poder", "outro" do poder, portanto, capazes de criticar a rede de relações e significações do poder sem ser contaminados pela ideologia que o estrutura.

Os enunciados que compõem o discurso crítico, no campo educacional, têm no conceito de ideologia um dos seus pilares: a ideologia, os sujeitos e os campos de saber são vistos como constituídos a partir de condições políticas. Nessa perspectiva, os discursos críticos minimizam ou não problematizam a qualidade do conhecimento ideológico e do conhecimento cientifico como instâncias construídas com base nas condições políticas de relações de poder; que "todo saber tem sua gênese em relações de poder". (MACHADO, 2000, p. XX).

Segundo a perspectiva da análise genealógica (FOUCAULT, 2000), a ciência não pode ser significada como "verdade", e a ideologia como um conhecimento "interessado", que obscurece a consciência dos indivíduos, dificultando uma visão "real" do mundo. Essa compreensão corresponderia a uma retórica salvacionista, que impõe ao sujeito que ele atinja um nível de "consciência política" capaz de transformar a si próprio e a sociedade em que vive, a partir do "desvelamento" do caráter "ideológico" da opressão a que estão submetidas as "classes dominadas". (SILVA, 2000).

São visões, segundo as quais, o sujeito e a consciência bem como as ações transformadoras a serem por ele implementadas são determinantes autônomos e soberanos, e, portanto fora das possibilidades de produção da linguagem no discurso, deixando de fora o poder como relação, distribuído na própria organização das forças produtivas.

Diferentemente da perspectiva de análise acrítica dos acontecimentos da vida em sociedade, os sujeitos são pensados como capazes de atingir uma consciência "clara" se instrumentalizados por uma visão crítica de mundo - suposta teoria da verdade - que os conduziria a um desvelamento do que estaria oculto no "mundo real". Portanto, uma "essência"-verdade deveria ser buscada sob ou por trás de algo que existe presentemente como "aparência". (SILVA, 2000) Mas, para Silva (2000) e Machado (2000), que se utilizam das ferramentas pensadas por Michel Foucault, ao longo de sua vasta e instigante obra, os sujeitos, o mundo social e a consciência são realidades cambiantes, porque resultam de produções do discurso, que é constituído na linguagem, que é um campo movediço, puro movimento.

Contrariamente à visão da pedagogia crítica marxista, que concebe o poder como algo que distorce, reprime e mistifica, Foucault vai nos apontar outra perspectiva de análise, na qual o poder é significado como produtor, como capaz de criar identidades e subjetividades, de modo que "as identidades e subjetividades assim produzidas não 
representam nenhuma distorção, nenhum desvio em relação a alguma essência humana que, deixada livre ou "bem" encaminhada, seguiria o seu "verdadeiro" curso". (DREYFUS \& RABINOW, 1995).

Ainda segundo a visão crítica, esse sujeito humano, autônomo e racional, é constituído por uma consciência prestes a ser colhida nas malhas do poder central, como o Estado, significado nesses discursos como "o" núcleo essencial do poder. (SILVA, 2000) Quando não ele, as "classes dominantes", enfim, "um" opressor. Nessa perspectiva, supõese a possibilidade de "uma situação de libertação, isto é, de não poder (e de) uma consciência unitária e autocentrada, embora momentaneamente alienada e mistificada, apenas à espera de ser despertada, desreprimida, desalienada, liberada, desmistificada". (ibidem, p. 249-252).

Os enunciados do "sujeito autônomo e consciente", livre das amarras do poder, aparecem fortemente representados na obra pedagógica de Paulo Freire, ${ }^{\text {vii }}$ cujos enunciados nucleares são a "conscientização", a "libertação", o "desvelamento"/ "a desocultação" das situações de opressão -, possibilitados por uma educação libertadora. Em uma de suas obras, Freire (1974) reconhece níveis diferenciados de consciência dos sujeitos: segundo uma gradação dialética e condições favoráveis de desalienação, parte-se da "consciência ingênua" para se chegar à "consciência crítica".

Outro aspecto da pedagogia crítica refere-se aos conteúdos veiculados nos livros, cheios de ideologia, e como são transmitidos aos alunos e alunas, caracterizando uma "educação bancária". O elemento mediador, nesse processo de desalienação e catalisador das mudanças na escola, seriam o professor e, fora, na sociedade, a prática política, mesmo que não necessariamente partidária.

Caracterizada como uma abordagem "sociocultural" no campo pedagógico, todo o percurso da sua produção esteve atrelado à cultura popular, movimento que teve seu início no pós-guerra na Europa, atrelado à problemática da democratização da cultura de modo geral. Nos países do Terceiro Mundo, nasce ligado aos movimentos sociais das camadas populares, sobretudo com os discursos e as práticas não discursivas da educação de adultos.

Segundo a visão libertadora freireana, a condição de transformação do/a homem/mulher em sujeitos está na dependência de sua capacidade de reflexão sobre o ambiente concreto em que vivem. Quanto mais refletem sobre a realidade, sobre a sua própria situação concreta, mais os sujeitos se tornam conscientes, comprometidos com uma intervenção social de mudanças. A ideia de consciência estava carregada, atravessada pela ideia de sua capacidade de desvelar - contínua e progressivamente - a realidade. Quanto maior o desvelamento da realidade, maior penetração na essência fenomenológica do objeto que se pretende analisar. (FREIRE, 1974).

Quanto ao papel da educação, Freire assevera que o seu objetivo central é prover o sujeito de condições de desenvolver uma atitude de reflexão crítica e comprometida com a ação. Para ele, a educação não está implicada necessariamente à escola como um lugar privilegiado de sua realização, pois as experiências que desenvolveu estavam ligadas ao próprio lugar onde se encontravam os sujeitos, aos movimentos sociais da educação de jovens e adultos, de modo que o processo ensino-aprendizagem seria um momento de superação do que ele chamava de "educação bancária", voltado à problematização das condições concretas de vida de cada um e de todos; de superação da relação opressoroprimido e de culminância da consciência crítica e da liberdade. 
Analisando as implicações da perspectiva crítica da educação, através da análise do discurso, de modo geral, ela está atravessada pela crença na existência de um conhecimento científico "verdadeiro" porque isento de ideologia e numa pedagogia transparente, livre do poder - este sempre com conotações carregadas de negatividade.

Nesses discursos, constrói-se uma oposição entre uma pedagogia tradicional e uma pedagogia progressista; no caso da pedagogia tradicional, com o eixo de sua prática recaindo sobre a relação professor/a-aluno/a, este/a último/a prisioneiro/a e subordinado/a ao autoritarismo do/a professor/a. A perspectiva do pode fica contaminada pela ideia de uma relação professor/a-aluno/a unilateral, - no caso específico da escola, sempre recaindo a "culpa" do poder sobre o professor.

Ainda segundo a visão crítica, somente ou principalmente através de uma prática pedagógica crítica e progressista, os alunos seriam conscientizados sobre a ideologia presente nos conteúdos escolares e nas ações, dentro e fora da escola e de seus fatores determinantes, atingindo uma "compreensão não mistificada da vida social, uma compreensão supostamente isenta de interesse de poder". (SILVA, 2000, p. 250).

Tal movimento das relações sociais, segundo a pedagogia crítica, possibilitaria libertar os sujeitos-alunos das agruras da falsa consciência e a desenvolverem uma consciência crítica, através de um trabalho emancipatório e de desvelamento propiciado pelo professor progressista.

O discurso crítico situa o nascimento dos saberes das ciências humanas - dos quais a escola se utiliza e respalda suas práticas discursivas e não discursivas - ou as suas condições de possibilidade na "infraestrutura", "viii, representada pelas condições econômicas dos sujeitos e dos grupos sociais, sendo a consciência o reflexo dessas condições. Tal compreensão subtrai o saber da sua condição de prática, de acontecimento, elemento de um dispositivo político que se articula com a estrutura econômica, a partir de práticas políticas disciplinares. (MACHADO, 2000).

Em se tratando de discursos sobre a educação - e a polissemia dos sentidos atribuídos ao "desempenho" das crianças, a partir de suas trajetórias na escola e de conceitos como o de fracasso escolar - ampliam-se as formas de poder sob a forma de um "bio-poder", que intercede sobre o corpo, sobre amplos estratos da população e que se realiza buscando regular a população, com o objetivo de gerir a vida do corpo social.

Nessas duas décadas analisadas, o bio-poder esteve representado pelos enunciados economicistas, consubstancializados na teoria do déficit cultural, do capital humano e nas teorias críticas. $\mathrm{O}$ discurso $\mathrm{e}$ as práticas não discursivas da pedagogia crítica problematizam a noção de fracasso escolar, com base em uma visão de "processoproduto", "entradas-saídas" e, nesse sentido, não se diferenciam dos enunciados da teoria liberal. Suas análises e práticas sublinham como causas do fracasso escolar, principalmente, os determinantes estruturais, que resvalariam nas condições dos alunos, das alunas e dos educadores, condições de trabalho nas escolas, material didáticopedagógico, organização do sistema de ensino, formação (deficitária) dos professores, entre outros.

Esses elementos, aos quais se deu grande ênfase, constituem-se os não ditos, os contradiscursos. Mesmo assim, alguns dos reconhecidamente respeitados discursos críticos reiteram estigmas e preconceitos sobre os padrões de comportamento das crianças pobres, tomando esses padrões segundo uma perspectiva de homogeneidade: "sujas", "desinteressadas", "apáticas", "carentes de afeto" etc., razão por que são feitas críticas aos professores (despreparados), não formados para lidar com essa realidade ausente dos 
conteúdos curriculares a partir dos quais foram formados, bem como a visibilidade que passa a ter a necessidade de se reestruturar a escola de modo a atender aos estratos sociais pobres da população.

Problematizando essas questões prementes, em que aspectos os discursos críticos diferiam da ideia de "educação compensatória" presente no ideário da teoria da privação cultural?

Em relação à teoria do capital humano, os discursos críticos não denegam alguns valores veiculados pela referida teoria, como a qualificação de recursos humanos que, mesmo quando dissociada da questão economicista, coloca a escola como instrumento imprescindível para as mudanças nos sujeitos, no seu grupo social e na sociedade. Também em ambas as perspectivas discursivas, as relações e a função da escola são determinadas pelos fatores extraescolares, macroestruturais, ou seja, os fatores econômicos.

As visões críticas produziram seus discursos dando também visibilidade ao fazer pedagógico, aos conteúdos veiculados pelo ensino, às relações que se estabelecem na escola; enfim, ao "porque" as maquinarias pedagógicas reproduzem as desigualdades existentes na estrutura social mais ampla e as relações entre as distintas classes. Desse modo, destacam aspectos relacionados às questões ideológicas, etnocêntricas e à transmissão de valores "inadequados" para a transformação das condições dos "dominados".

Como bem destaca Larrosa (1998, p. 46-75), essa se constitui uma crítica eminentemente moral, pois significa "certa confiança na possibilidade de transformar 'isso' que, segundo parece, transmitem as formas dominantes de educação. Trata-se somente de pedagogizar a "boa doutrina"' (ibidem, p. 13). Ainda segundo esse autor, os discursos críticos secundarizam a importância de se problematizar o "como" da pedagogia, ao "que fazer" da prática pedagógica, no sentido de analisar a estrutura e o funcionamento dos próprios dispositivos pedagógicos.

Para dar visibilidade aos discursos da pedagogia crítica sobre o fracasso escolar, tomo como discurso representativo para sua análise obras de Maria Helena Souza Patto $(1984 ; 1986 ; 1996)$, por ter sido a autora brasileira de maior reconhecimento no campo acadêmico que introduziu o materialismo histórico ${ }^{\mathrm{ix}}$ ao problematizar o fracasso escolar.

Já desde a sua primeira obra, seus discursos se articulavam à teoria da privação cultural (1984; 1986), até a última publicação (da Tese de doutoramento): "A produção do fracasso escolar: histórias de submissão e rebeldia (1996). É sobre esta última produção, que se tornou clássica no campo educacional, que incidirão as análises.

$\mathrm{Na}$ sua primeira parte, a obra trata da literatura relacionada ao que a autora concebe como "causas do fracasso escolar" e uma análise das "raízes históricas" das concepções sobre essa temática. A segunda parte do livro trata da própria pesquisa realizada em uma escola pública de primeiro grau, na cidade de São Paulo, entre 1976 e 1979, cujo objetivo era "definir a sua natureza (refere-se ao fracasso escolar), através da análise de seu discurso no que ele diz, no que ele não diz e no que se contradiz". (1996, p. 3, grifos do original)

Patto (1996) chama à atenção, sobretudo, para a relevância dos aspectos históricos do discurso do fracasso escolar, apontando para a questão do poder, o "como" da prática pedagógica, no sentido de totalidade, em que esses elementos se relacionam dialeticamente e numa perspectiva determinista, mas secundariza a análise da estrutura e do funcionamento dos próprios dispositivos pedagógicos como imbricados em relações de poder-saber. ${ }^{\mathrm{x}}$ 
Por outro lado, mesmo diferenciando-se dos discursos que compunham o paradigma liberal da educação e na perspectiva da teoria da privação cultural, a produção de Patto merece ser analisada em seus aspectos e enunciados fundamentais, para que possamos ler as regularidades e descontinuidades dos paradigmas, a sua produção e as questões construídas pela narrativa crítica.

Seu discurso "diferenciado" coloca o fracasso escolar como um fenômeno resultante das políticas econômicas e sociais desenvolvidas pelo "sistema". O fracasso da escola pública elementar seria um fenômeno recorrente, resultado inexorável de um sistema educacional gerador de obstáculos para a realização de seus objetivos. Em seus escritos, a autora não denega o conceito de fracasso escolar atrelado às crianças das camadas populares, pois o reconhece como uma "realidade" presente no ensino público.

As explicações do fracasso escolar baseadas nas teorias do déficit e da diferença cultural precisam ser revistas a partir do conhecimento dos mecanismos escolares produtores de dificuldades de aprendizagem [...] $\mathrm{O}$ fracasso da escola pública elementar é o resultado inevitável de um sistema educacional congenitamente gerador de obstáculos à realização de seus objetivos. [...] Reprodução ampliada das condições de produção dominante nas sociedades que as incluem, as relações hierárquicas de poder, a segmentação e a burocratização do trabalho pedagógico, marcas registradas do sistema público de ensino elementar, criam condições institucionais para a adesão dos educadores à singularidade, a uma prática motivada acima de tudo por interesses particulares, a um comportamento caracterizado pelo descompromisso social. (ibidem, p. 340 e segs., grifos do original).

A autora questiona a noção de fracasso escolar interpretada pela vertente da privação cultural, quando considera essa articulação uma "meia-verdade" - o que sugere uma crença da autora na existência de um conhecimento verdadeiro sobre o fracasso escolar. Em seus escritos, a mesma não denega o conceito de fracasso escolar atrelado às crianças das camadas populares, pois o reconhece como uma "realidade" presente no ensino público. Ao interpretar a noção de fracasso escolar o faz pela vertente da privação cultural, quando considera essa articulação uma "meia-verdade" - o que sugere uma crença na existência de um conhecimento "verdadeiro" sobre o fenômeno do fracasso escolar.

Patto (1996) concebe que o problema reside em um modo determinado de produzir ciência, que unifica o conhecimento científico com os saberes ordinários, impossibilitando a atuação de outra forma de produzir conhecimento capaz de desvelar a ideologia presente na sociedade e na prática escolar: [...] "longe de serem meras opiniões gratuitas, essas ideias ganham força ao serem confirmadas por um determinado modo de produzir conhecimentos, que alça opiniões do senso comum ao nível das verdades científicas inquestionáveis" (ibidem, 1996, p. 341).

A autora trata o discurso do fracasso escolar como de uma "verdade", sem problematizar sua invenção como um dispositivo construído em intrincadas redes de relações de poder e como maquinaria de governo que é produtiva ao sistema educacional e político. O poder é tratado fora das relações, como algo que se outorga ou que se tira de alguém; como algo que é apropriado por alguém ou por alguns como uma riqueza ou um bem. Assim, a autora desconsidera que "o poder funciona e se exerce em rede [e que], nas 
suas malhas, os indivíduos não só circulam, mas estão sempre em posição de exercer esse poder e de sofrer sua ação; nunca são o alvo inerte ou consentido do poder, são sempre centros de transmissão. [...] o poder não se aplica aos indivíduos, passa por eles" (FOUCAULT, 2000, p. 183).

Patto adota o discurso da "diferença cultural" e, em alguns casos da própria teoria que critica, a teoria da privação cultural, presente em várias partes do seu texto: "A inadequação da escola decorre muito mais de sua má qualidade, da suposição de que os alunos pobres não têm habilidades que, na realidade, muitas vezes (supõe, portanto, que outras vezes isso não ocorre) possuem" (PATTO, 1996, p. 340.): [...] "O contato direto e prolongado com crianças de bairros periféricos mostra que elas constituem um grupo heterogêneo, que elas diferem entre si, e que falar em "criança carente", no singular, é uma generalização indevida". (ibidem, p. 341 grifos do original)

Portanto, a diferença entre esses dois discursos está nos horizontes que cada um deles aponta: enquanto no discurso da privação cultural as formas de solução para o problema de rendimento escolar e as mudanças são individualizadas no aluno e na família e, para tal, sugerem-se as políticas compensatórias, no discurso crítico analisado, o discurso de Patto, a escola é como potencialmente responsável pelo fracasso escolar dos alunos: "É, no mínimo, incoerente concluir, a partir de seu rendimento, numa escola cujo funcionamento pode estar dificultando, de várias maneiras, sua aprendizagem escolar, que a chamada "criança carente" traz inevitavelmente para a escola dificuldades de aprendizagem". (PATTO, 1996, p. 340, grifos do original)

Segundo o discurso reprodutivista de Patto, no qual ELA não se reconhece, a mudança a ser buscada é, ao nível do contexto econômico, mais amplo, como totalidade na qual se incluem os fatores intraescolares: "a compreensão do fracasso escolar, enquanto um processo psicossocial complexo, no qual estão envolvidos os alunos e suas famílias", quando considera o sistema público de ensino elementar como "reprodução ampliada das condições de produção dominantes na sociedade que as inclul” (ibidem, p. 343).

Patto também considera a escola, ao mesmo tempo, como potencialmente capaz de, utilizando-se das "brechas" do poder e através do desvelamento dos conteúdos ideológicos presentes nas relações de opressão que se estabelecem no seu interior e fora, na sociedade, ser também uma mediação para as transformações a serem realizadas nesses contextos. Nesse processo, o professor progressista teria um papel fundamental, que ela sublinha retomando alguns conceitos de Agnes Heller - como o "interlocutor qualificado" que acompanharia os educadores na desocultação do real: "interlocutor qualificado que venha a colaborar com grupos de educadores na superação da maneira irrefletida, estereotipada, preconceituosa, pragmática e sem perspectiva humano-genérica com que lidam com a tarefa de ensinar" (ibidem, p. 352).

Patto critica o conhecimento positivista, mas não se desvencilha de suas malhas ao supervalorizar o conhecimento científico, desqualificando outros saberes tomados como "falso conhecimento", como se pode ver nessa passagem de seu discurso:

[...] produz resultados que não dão conta da complexidade do que quer que se proponha elucidar a respeito da vida humana, como resulta em conhecimentos que se detêm na aparência, que ocultam a essência dos fenômenos que examina e que, por isso mesmo, não passam de pseudoconhecimentos. [...] o conhecimento tem início pela resistência ao senso comum e aos estereótipos. A ciência que se detém no imediatamente dado gera explicações que não passam de "ideologia 
disfarçada" em conhecimento acima de qualquer suspeita. (PATTO, 1984, p 157).

Estão ausentes nesses fragmentos do seu discurso as possibilidades colocadas pela linguagem e que aparecem nos não ditos dos discursos ou no que eles silenciam; ao invés disso, suas narrativas são construídas a partir de essencialismos, da ideia de ideologia como falso conhecimento da realidade. Essa é, aliás, uma característica dos discursos críticos e de esquerda, de modo geral, ao se colocarem como fora das relações de poder, como discursos de verdade. Sobre esse aspecto, Foucault vai dizer que

O problema político essencial para o intelectual não é criticar os conteúdos ideológicos que estariam ligados à ciência ou fazer com que a sua prática científica seja acompanhada por uma ideologia justa, mas saber se é possível constituir uma nova política de verdade. O problema não é mudar a consciência das pessoas ou o que elas têm na cabeça, mas o regime político, econômico, institucional de produção da verdade (FOUCAULT, 2000b, p. 14).

Em relação ao lugar ou à identidade do sujeito que "fracassa" na escola, toda a construção discursiva de Patto é um reflexo dos elementos considerados anteriormente, quando tratei do marxismo e da filosofia da consciência; um marxismo que "aspira ao discurso da verdade, à superação definitiva do discurso lacunoso da ideologia, à substituição definitiva das máscaras discursivas que encobrem o rosto do real" (ALBUQUERQUE JÚNIOR, 2001, p. 234.). Nesse processo, o sujeito autocentrado e consciente teria um grande papel a desempenhar.

A análise dos discursos sobre as crianças com trajetórias minoritárias na escola, classificadas como crianças que fracassam na escola, seja em sua vertente liberal, seja no veio da privação cultural ou, ainda, da diferença cultural e/ou numa perspectiva crítica, traz, implícita ou explicitamente, a ideia de uma "teoria total da sociedade"; de um "indivíduo humano como centro e origem do pensamento e da ação" (SILVA, 2000, p. 14), de um sujeito homogêneo, a-histórico.

Parte significativa dos discursos que se propunham subversivos à ordem estabelecida, cuja produção teve visibilidade através dos saberes da Psicologia e da Pedagogia, estabelecidos pelo regime de verdade dos anos de 1960/1970, enfocavam a "liberdade", a criança como "pessoa", como "agente autônomo", mas se baseavam, igualmente, em sistemas de classificação e regulação.

Muitas perspectivas discursivas correntes nas metanarrativas modernas não concretizaram a pretensão de liberdade, de progresso tão fortemente presentes em seus enunciados e lutas sociopolíticas, mas, como nos informam muitos estudiosos, criaram novas formas de aprisionamento dos sujeitos. E as ciências humanas e a educação escolar, particularmente, instituem-se como dispositivos fundamentais para a criação de práticas não discursivas, maquinarias de governo que vitimizaram subjetividades pela necessidade de classificar, medir, comparar, controlar - tal como fica caracterizado pela centralidade do sujeito/aluno/a historicamente na produção do discurso do fracasso escolar.

A visão da sociedade como "totalidade", como "treva" a ser desvelada e iluminada e a identidade cartesiana de um (suposto) sujeito centrado, consciente, enfim, moderno 
foram destituídas de adjetivações petrificadas, porque o sujeito quer mais, muito mais, configurando uma nova perspectiva ainda imperceptível pela escola. Um sujeito que "escapa" aos aprisionamentos classificatórios na atualidade: um "mutante do desejo", cujas formas de existência são objetos de pesquisas, de embates no campo das ideias e das epistemologias.

Bom começo!

\section{Referências}

ALBUQUERQUE JÚNIOR. Durval M. A invenção do nordeste e outras artes. 2. ed. Recife: FJN, Massangana; São Paulo: Cortez, 2001.

BUJES, Maria I. E. Governando a subjetividade: a constituição do sujeito infantil no RCN/EI. Revista Pro-posições, vol. 13, n.1 (37), jan/abr. 2002.

Alguns apontamentos sobre as relações infância/poder numa perspectiva foucaultiana. In: Reunião Anual da Associação Nacional de Pós-graduação e Pesquisa em Educação (26 R. A. ANPEd), 2003, Poços de Caldas (MG). CD-ROM da $26^{a}$ Reunião Anual da Associação Nacional de Pós-graduação e Pesquisa em Educação (ANPEd). Rio de Janeiro (RJ): Associação Nacional de Pós-graduação e Pesquisa em Educação (ANPEd), 2003. p. 1-13.

CASTORIADIS, Cornelius. O mundo fragmentado: as encruzilhadas do labirinto. Tradução de Rosa Maria Boaventura. Rio de Janeiro: Paz e Terra, 1992. 294p.

CORAZZA, Sandra M. Que quer um currículo? Pesquisas pós-críticas em educação. Petrópolis: Vozes, 2001.

Labirintos da pesquisa, diante dos ferrolhos. In: COSTA, Marisa V. (Org.) Novos olhares na pesquisa em educação. In: Caminhos investigativos: novos olhares na pesquisa em educação. 2 ed. Rio de Janeiro: DP\&A, 2002.

DREYFUS, Hubert L. \& RABINOW, Paul. Michel Foucault: uma trajetória filosófica para além do estruturalismo e da hermenêutica. Tradução de Roberto Machado. Rio de Janeiro: Forense Universitária, 1995. 327 p.

FOUCAULT, Michel. Os intelectuais e o poder. In: Microfísica do poder. Tradução de Roberto Machado. 15. ed. Rio de Janeiro: Graal, 2000a. 295 p. A arqueologia do saber. Rio de Janeiro: Forense Universitária, 2000b. 239 p.

FREIRE, Paulo. Conscientización. Buenos Aires: Ediciones Busqueda, 1974. 87 p.

LARROSA, Jorge. A construção pedagógica do sujeito moral. In: SILVA, Tomaz T. da. Liberdades reguladas: a pedagogia construtivista e outras formas de governo do eu. Petrópolis: Vozes, 1998, p. 46-75. 
MACHADO, Roberto. Por uma genealogia do poder. In: FOUCAULT, Michel. Microfísica do poder. Tradução de Roberto Machado. 15. ed. Rio de Janeiro: Graal, 2000. $295 \mathrm{p}$.

MARTINS, Pura L. O. A relação conteúdo-forma: expressão das contradições da prática pedagógica na escola capitalista. In: VEIGA, Ilma P. A. (Org.). Didática: o ensino e suas relações. Campinas, SP: Papirus, 1996.

MELLO, Thiago de. Faz escuro mas eu canto. Rio de Janeiro. Civilização Brasileira, 1978.

PATTO, M. H. S. Psicologia e ideologia. São Paulo: T. A. Queiroz, 1984.

Introdução à psicologia escolar. São Paulo: T. A. Queiroz, 1986.

A produção do fracasso escolar: histórias de submissão e rebeldia. São Paulo: T.A. Queiroz, 1996.

POPKEWITZ, Thomas S. Reforma educacional e construtivismo. In: SILVA, Tomaz T. da. (Org.). Liberdades reguladas: a pedagogia construtivista e outras formas de governo do eu. Petrópolis, RJ: Vozes, 1998. 216 p.

QUEIROGA, Maria do Socorro N. O discurso do fracasso escolar como tecnologia de governo da infância: a arqueologia de um conceito. 2005. f. 442. (Tese de Doutorado em Sociologia) - Centro de Ciências Humanas e Sociais, Universidade Federal da Paraíba, João Pessoa.

O discurso do fracasso escolar: a arqueologia de um conceito. In: Anais do II Colóquio Internacional de políticas e práticas curriculares. p. 1-6, João Pessoa, Nov. 2005b. (CD-ROM).

Governando a infância para regenerar a raça: arqueologia do discurso eugenista em educação. In: Anais do VI Congresso luso-brasileiro de história da educação. p. 23122322, Uberlândia, Abr. 2006. (CD-ROM).

O governo dos escolares e a produção do discurso do fracasso escolar. Colóquio brasileiro de educação na sociedade contemporânea (COBESC). p. 810-816, Campina Grande, PB, Jun. 2008. (CD-ROM).

De servos de Deus a escolares: a trajetória da infância como problema. II Colóquio internacional educação e contemporaneidade. p. 1-14, Aracaju, SE, Set. 2008. (CD-ROM).

Da infância livre à infância "inadaptada": apontamentos sobre a produção do discurso do fracasso escolar. II Colóquio internacional educação e contemporaneidade. p. 1-16, Aracaju, SE, Set. 2008. (CD-ROM). 
Da infância livre à infância inadaptada: apontamentos sobre o disciplinamento da infância. João Pessoa, PB. (EPPEN-2009). (Mar/2009a).

O governo dos corpos infantis: a produção e a distribuição do discurso da eugenia no campo da educação. (mimeo). (Trabalho aprovado para publicação na Revista VIVÊNCIA- ISSN 0104-3064. Centro de Ciências Humanas, Letras e Artes, UFRN). (Abr/2009b).

O discurso do fracasso escolar: cenário da sua emergência no Brasil. Artigo submetido à aprovação para o VIII Congresso Luso-brasileiro de História da Educação, a ser realizado no Maranhão em agosto/2010. (mimeo).

SILVA, Tomaz, T. O adeus às metanarrativas educacionais. In: SILVA, Tomaz T. (Org.). O sujeito da educação: estudos foucaultianos. 4. ed. Petrópolis: Vozes, 2000a.

Monstros, ciborgues e clones: os fantasmas da pedagogia crítica. In:

(Org.). Pedagogia dos monstros: os prazeres e os perigos da confusão de fronteiras. Belo Horizonte: Autêntica, 2000b. 199 p.

TAMBARA, Elomar. Karl Marx: contribuições para a investigação em História da educação no século XXI. In: FARIA FILHO, Luciano F. (Org.). Pensadores sociais e história da educação. 2. ed. Belo Horizonte: Autêntica, 2008. 342 p.

VEIGA, Ilma P. A. (Org.). Didática: o ensino e suas relações. Campinas, SP: Papirus, 1996. $278 \mathrm{p}$.

${ }^{i}$ Refiro-me à produção da Tese de Doutorado e aos artigos científicos produzidos recentemente. Na Tese, intitulada "O discurso do fracasso escolar como tecnologia de governo da infância: arqueologia de um conceito", realizo uma análise arqueológica e genealógica do conceito de fracasso escolar, a partir dos discursos sobre as crianças com histórias de trajetórias minoritárias na escola (2005b; 2006;2008a; 2008b; 2009a; 2009b). Criei essa terminologia para me referir às crianças e aos adolescentes que compõem as estatísticas oficiais e se constituem em personagens dos discursos pedagógicos que tratam do fracasso escolar - representado pelos índices de repetência, reprovação e evasão da escola. Este artigo foi originariamente aprovado para a IX Jornada do HISTEDBR - História, Sociedade e Educação no Brasil ocorrido recentemente, (7/07/2010), em Belém / PA.

${ }^{\text {ii }}$ Utilizo aqui a noção de ideologia para significar modo de pensar, visão de mundo.

${ }^{\text {iii }}$ Quando era significativa a exclusão dos indivíduos das classes populares da escola.

iv Nesse sentido, foram criados dispositivos de regulação, como o Programa Nacional de Ações Socioeducativas e Culturais para o Meio Rural (PRONASEC) e o Programa de Ações Socioeducativas e Culturais para as Populações Carentes Urbanas (PRODASEC), através do III PSECD de 1980-1985. (GERMANO, 2000)

${ }^{v}$ As produções da época, legitimadas pelo discurso estatístico, destacavam que, no Nordeste, o número de professores leigos, com apenas o primeiro grau, chegava a 36,0\% em 1981; a taxa nacional de repetência, na primeira série do primeiro grau, passava de $27,2 \%$, em 1973, para 34,2\%, em 1983; e, juntando com os índices de evasão, totalizavam $42,6 \%$, para a primeira série, e de $35,2 \%$, para a segunda série, o que significava os mesmos índices de mais de uma década atrás. Mais de $60 \%$ da população economicamente ativa era formada por indivíduos que nunca foram à escola e aqueles que estudaram durante apenas quatro anos, portanto, com apenas instrução primária. Em 1986, 30\% da população - quinze milhões de pessoas - entre dez e dezessete anos, estava inserida no mercado de trabalho, recebendo, em média, $20 \%$ do salário mínimo por uma jornada de quarenta horas na maioria dos casos, o que os retirava da escola precocemente (GERMANO, 2000). 
${ }^{\mathrm{vi}}$ As obras mais discutidas e incorporadas pelo ideário pedagógico escolar foram produzidas por alguns estudiosos como: Dermeval Saviani, Bárbara Freitag, Luís Antônio Cunha, Vanilda Paiva, Moacir Gadotti, Cláudio Salm, Gaudêncio Frigotto, Darcy Ribeiro, Carlos Jamil Cury, Otaiza Romanelli, Florestan Fernandes, entre outros. Quanto à produção internacional, sobressai o pensamento de Karl Marx, de modo geral, o de Antonio Gramsci, o de Pierre Bourdieu e o de Louis Althusser.

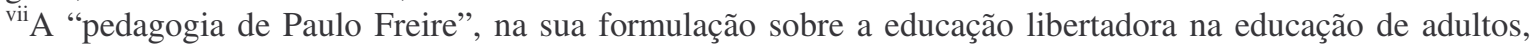
pode ser considerada a maior expressão dessa segunda perspectiva do discurso marxista. Penso que o pensamento freireano seria um documento suficiente para a produção de outra Tese de Doutorado. Mas quero deixar registrada a minha homenagem a um dos maiores distribuidores de utopias educacionais, cujo discurso, veiculado em ampla literatura pedagógica na perspectiva "libertadora da educação", foi fundamental para a produção de novos discursos e práticas não discursivas, os quais possibilitaram senão uma ruptura, mas uma descontinuidade nas práticas educacionais de exclusão vigentes em um tempo de desesperança.

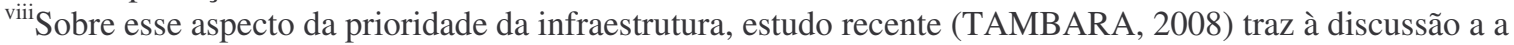
rica e instigante possibilidade de retomarmos a própria visão de Karl Marx sobre a superestrutura, nos estudos no campo da educação.

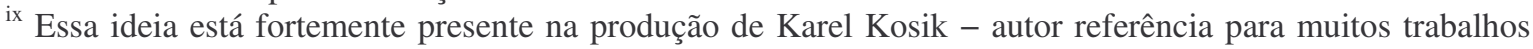
desenvolvidos até bem recentemente no campo educacional - sobretudo em sua obra intitulada Dialética do concreto. Rio de Janeiro: Paz e Terra, 1979.

'Para a reflexão ora em curso, foram de fundamental importância algumas leituras e obras (BUJES, 2002; 2003; CORAZZA, 2001; 2002; SILVA, 2000a, 200b).

Artigo recebido em: 10/06/2010

Aprovado para publicação em:12/07/2010 